\title{
The phage T4 nrdB intron: a deletion mutant of a version found in the wild
}

\author{
Sean R. Eddy and Larry Gold \\ Department of Molecular, Cellular, and Developmental Biology, University of Colorado, Boulder, Colorado 80309-0347 USA
}

\begin{abstract}
Bacteriophage T4 possesses three self-splicing group I introns. Two of the three introns are mobile elements; the third, in the gene encoding a subunit of the phage nucleotide reductase (nrdB), is not mobile. Because intron mobility offers a reasonable explanation for the paradoxical occurrence of large intervening sequences in a space-efficient eubacterial phage, it is puzzling that the nrdB intron is not mobile like its compatriots. We have discovered a larger $n \mathbf{n} B$ intron in a closely related phage, and we infer from comparative sequence data that the $\mathrm{T} 4$ intron is a deletion mutant derived from this larger intron. This larger nrdB intron encodes an open reading frame of 269 codons, which we have cloned and overexpressed. The overexpressed protein shows a dsDNA endonuclease activity specific for the intronless nrdB gene, typical of mobile introns. Thus, we believe that all three introns of $\mathrm{T} 4$ are or were mobile "infectious introns" and that they have entered into and been maintained in the phage population by virtue of this efficient mobility.
\end{abstract}

[Key Words: Bacteriophage T4; nrdB intron; endonuclease mobility]

Received January 2, 1991; revised version accepted March 4, 1991.

It is generally true that prokaryotic genes do not have introns. Because prokaryotic genomes tend to be smaller and replicate faster than eukaryotic genomes, it is thought that introns and other nonessential DNA sequences have been kept out of prokaryotes by selective pressure to streamline the genome (for particularly cogent reviews of this controversial topic, see Doolittle 1987; Hickey et al. 1989).

An extreme exception is the occurrence of three group I introns in the Escherichia coli bacteriophage T4 (for review, see Belfort 1990). Phage T4 has a 166-kb DNA genome, which otherwise appears to be highly streamlined; for example, promoters and even translational initiation regions are often found to lie nested within the coding sequence of upstream genes. That these three introns remain in the space-efficient T4 genome may suggest that there is some selective pressure keeping them there.

The introns occur in the genes encoding the phage dTMP synthase $(t d)$, the small subunit of the phage nucleotide reductase $(n r d B \mid$, and a protein of unknown function called sunY. It is curious that the two proteins of known function catalyze steps in the same pathwayde novo dNTP synthesis from rNTP pools-and, furthermore, that they lie at the only two steps that consume reducing equivalents (ultimately $\mathrm{NADPH}$ ) from the reserves of the host cell. (Although sunY encodes an unknown function, it lies very close to $n r d C$, the phage thioredoxin.) Group I splicing itself relies on an exogenous ribonucleotide and may be inhibited by guanosine analogs; most cofactors involved in redox transactions are analogs of nucleotides and are often derived directly from adenosine or guanosine (White 1983). These facts have led to speculation that these introns are involved in a feedback regulatory loop that controls the level of dNTP synthesis in the infected cell and, therefore, confer a selective advantage upon intron-containing phage (Gott et al. 1986; Goodrich-Blair et al. 1990).

A different (but not incompatible) hypothesis proposes that the introns are mobile genetic elements. This was suggested by the inconsistent occurrence of the introns in the closely related phages $\mathrm{T} 2$ and $\mathrm{T} 6$ / T2 has no introns, and T6 has only the $t d$ intron) (Pedersen-Lane and Belfort 1987; Quirk et al. 1989a). This hypothesis has been substantiated by recent direct experimental evidence demonstrating that the $t d$ and sun $Y$ introns are indeed actively mobile (Quirk et al. 1989b); both introns encode DNA endonucleases highly specific for intronless $t d$ (Bell-Pedersen et al. 1989, 1990; Chu et al. 1990) or sun $Y$ (Bell-Pedersen et al. 1990) genes. The resulting double-stranded DNA (dsDNA) breaks appear to initiate an efficient unidirectional gene conversion event, resulting in the conversion of intronless to intron-plus genes in a mixed infection. This high-frequency conversion to intron-plus genes might be expected to easily maintain the introns in the phage population, even in the face of other selective pressures to remove them.

Group I intron mobility appears to be a general phenomenon (Dujon 1989a; Perlman and Butow 1989; Scazzocchio 1989). Examples of mobile group I introns now include the yeast mitochondrial $\omega$ (Jacquier and Dujon 1985) and aI4 (Delahodde et al. 1989; Wenzlau et al. 1989) introns, a nuclear rRNA intron in Physarum (Muscarella and Vogt 1989), and a chloroplast rRNA intron in 
Chlamydomonas (Lemieux et al. 1988). Intron mobility may explain apparent horizontal transfer events, in which very similar introns have been found in homologous sites of genes in highly divergent organisms (e.g., Lang 1984; Trinkl and Wolf 1986).

Although high-frequency intron mobility may account for the presence of the $t d$ and sunY introns in T4, it fails to explain the presence of the immobile $n r d B$ intron. As ribonucleotide reductase catalyzes the first committed step to phage dNTP synthesis, the nrdB intron should be central to any regulation of this process at the level of mRNA splicing. If anything more than intron mobility were maintaining introns in $\mathrm{T}$-even phage populations, we would expect to learn about it from $n r d B$.

We describe here our fortuitous discovery that a wild phage isolate called RB3 possesses a similar but longer intron in its $n r d B$ gene. Unlike the 598-bp T4 intron, this 1091-bp RB3 intron encodes a long open reading frame (ORF) of similar length and composition to those encoded by other mobile introns. The RB3 intron ORF produces a DNA endonuclease that targets an intronless $n r d B$ gene, a hallmark of a mobile group I intron. We think that the T4 nrdB intron is not mobile because it is a deletion mutant of this intron. We propose that all three T4 introns were "infectious introns" (Lambowitz 1989) inserted in the phage genome and maintained there (at least in part) by virtue of an efficient intron mobility mechanism.

\section{Results \\ PCR fingerprinting of phage isolates}

We were interested in surveying the distribution of introns in wild phage populations. We devised a simple polymerase chain reaction (PCR)-based fingerprinting technique to screen single plaques from the wild and find new $T$-even phages. We used an existing collection of T-even phages-the RB strains, collected from Long Island, New York, in 1964-as positive controls in the development of this PCR fingerprinting screen.

The PCR fingerprints used 10 amplification primers directed at regions of five strategically chosen $\mathrm{T} 4$ genes. Two were chosen as genes expected to be highly conserved among T-evens: genes 32 and 43, which encode the single-stranded DNA-binding protein and the DNA polymerase of the phage and which are both required for phage replication. We expected nearly every T-even isolate to possess enough sequence similarity to genes 32 and 43 of $\mathrm{T} 4$ that we could amplify one or both of these diagnostic fragments. The other three target genes were the three known intron-containing genes $t d, n r d B$, and sun $Y$. These amplification primers annealed to exon sequence on either side of the intron insertion point, so the fingerprint of an intron-plus phage would show a large PCR product and the fingerprint of an intronless phage would show a small PCR product. We used this mixed 10-primer set to simultaneously amplify fragments from the DNA in resuspended phage plaques.

Figure 1 shows the fingerprints of six of the seven clas- sic $\mathrm{T}$ phages. The technique easily distinguishes a $\mathrm{T}$ even plaque from the plaques of other $\mathrm{T}$ phages. However, because some $\mathrm{T}$-even phage may have diverged sufficiently from T4 that some primers fail to anneal, we did not expect to detect all five diagnostic bands from every phage isolate. For example, note that we failed to pick up the intron-plus $t d$ gene or the intronless $n r d B$ gene in T6.

We PCR-fingerprinted 24 phage from the RB collection that were available to us. All 24 phage gave positive fingerprints of from two to five of the expected bands, so we considered the technique adequate for the purpose of screening and rapidly isolating more $\mathrm{T}$-even phage from the wild (S.R. Eddy, L. Zwerdlinger, and L. Gold, unpubl.). We were surprised to find that 7 of the 24 phage reproducibly gave a band of unexpectedly large size, and we followed up this observation.

Figure 1 shows the PCR fingerprint of a representative of these seven phage, RB3. Because the fingerprint of RB3 showed the other four products at their expected sizes, we could guess that the larger band was produced from the $n r d B$ gene of these phage. Figure 1 also shows that the large product is indeed amplified by the $n r d B$-specific primers alone. Restriction mapping of this PCR fragment indicated that it contained a sequence differing from that of $\mathrm{T} 4$ by an insertion of $\sim 500 \mathrm{bp}$ in the amino-terminal part of the $n r d B$ intron ORF.

The T4 nrdB intron ORF has been enigmatic. It is actually composed of two overlapping ORFs: A short, 22codon ORF with a translational initiation region blocked by a strong putative secondary structure (a characteristic shared with the other two intron ORFs in T4) overlaps a longer 97-codon ORF with no convincing translational initiation region of its own. The 97-codon ORF possesses a lysine/arginine-rich amino acid composition and two repeats of a zinc-finger-like sequence at its carboxyl terminus (Gott et al. 1986, 1988; Shub et al. 1988; Liu 1990). $\beta$-Galactosidase protein fusions into both of these frames had shown activity only from the shorter ORF and none from the longer ORF (Gott et al. 1988; Liu 1990). Ribosomal toeprinting experiments (D. McPheeters and L. Gold, unpubl.) also indicated that the UUG start of the 22-codon ORF was an efficient translational initiation region but that the AUG of the 97-codon ORF was not. These observations led to the suggestion that certain conditions might lead to a ribosomal frameshift event that fused the products of the two reading frames (Gott et al. 1988; Liu 1990). However, the insertion (relative to T4) in the RB3 intron puts the 22 -codon ORF and the 97-codon ORF into the same long reading frame, that is, the T4 intron contains a deleted copy of the RB3 intron ORF.

\section{Sequence of the new intron}

Using template produced by asymmetric PCR amplification of genomic RB3 phage DNA, we sequenced the entirety of the PCR product produced by $n r d B$-specific fingerprinting primers. As shown in Figure 2, the sequence is virtually identical to that of the $\mathrm{T} 4$ intron, except for 


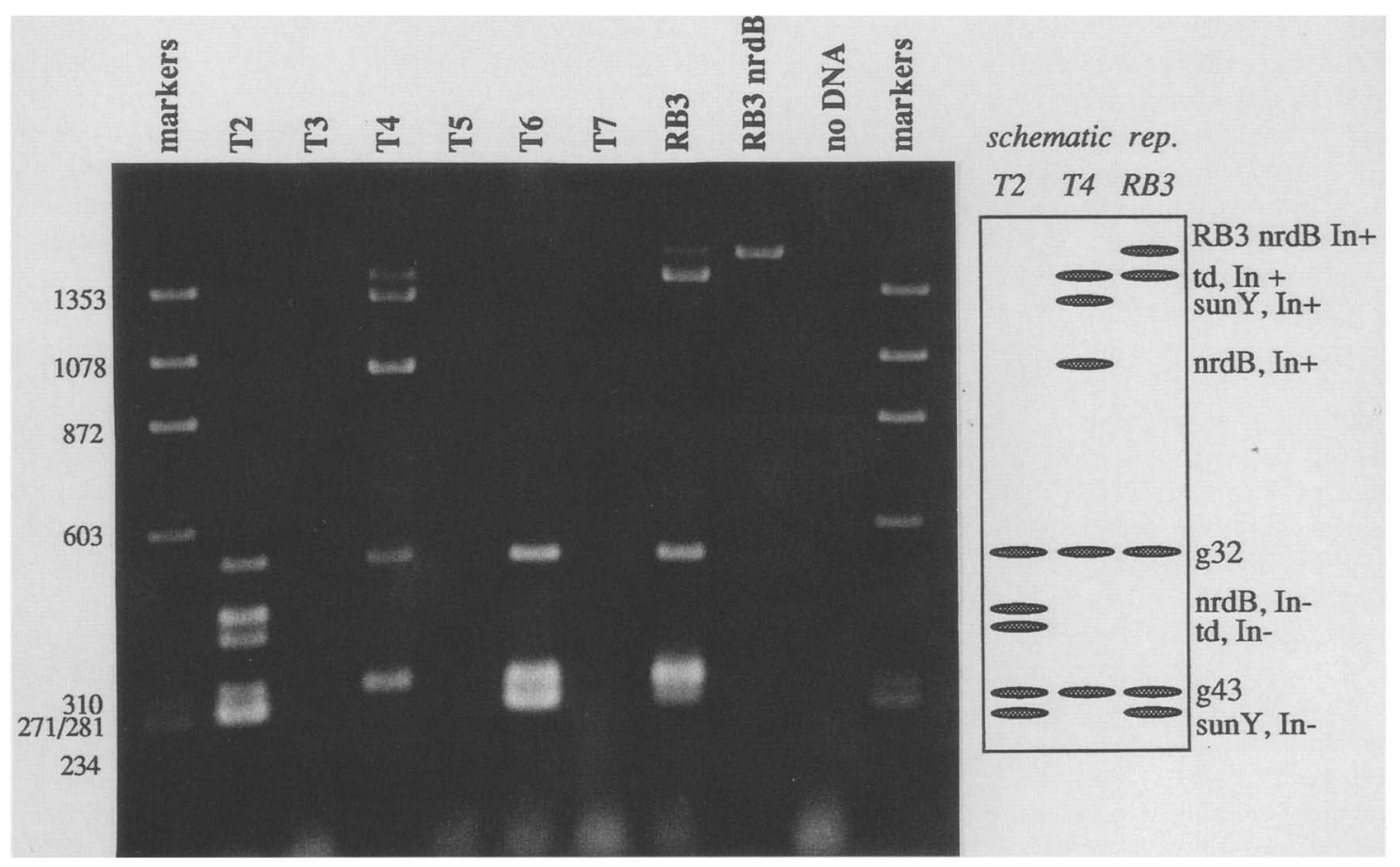

Figure 1. PCR fingerprints of phage plaques. Single plaques of the classical phages T2, T3, T4, T5, T6, and T7 were picked from plates and fingerprinted as described in Materials and methods. As expected, only the T-even phages generate fingerprints. Shown next is the fingerprint of the wild isolate RB3 and then a conventional PCR using just the two nrdB-specific PCR primers, illustrating that the $n r d B$ intron-containing fragment amplified from RB3 is significantly larger than was expected. (Right) A representation of the expected band arrangements from the intron-containing phage T4 and the intronless phage T2, as well as the fingerprint of RB3.

$491 \mathrm{bp}$ of new sequence in the intron ORF. As expected, this new sequence puts the two short T4 $n r d B$ ORFs in the same long reading frame. The RB3 $n r d B$ intron is predicted to encode a 269 -amino-acid protein with a molecular mass of $\sim 31 \mathrm{kD}$.

This predicted protein has features characteristic of some DNA-binding proteins. First, it is highly basic, possessing a large number of lysine and arginine residues. Second, as was noticed in the longer of the T4 ORFs, it has two carboxy-terminal zinc-finger-like motifs of the form CxxC-[12-13]-HxxxC. A search of the NBRF protein data base (release 25) using the FASTA algorithm of Pearson and Lipman (1988), and a TFASTA search of the GenBank nucleic acid data base (release 64), revealed no convincing sequence similarity to known protein sequences. The sequence does not show the LAGLIDADG motif characteristic of most intron ORFs (Hensgens et al. 1983; Waring et al. 1984) nor does it show the GIY-YIG motif shared by the $t d$ intron ORF and some fungal mitochondrial intron ORFs (Burger and Werner 1985; Michel and Dujon 1986; Cummings et al. 1989). Furthermore, although retroviral endonucleases (e.g., integrases|, as well as some group II intron ORFs, often possess carboxy-terminal zinc-finger-like sequences (Doolittle et al. 1989|, the RB3 nrdb intron ORF sequence showed little similarity to these protein sequences.

The nucleotide sequence suggests how the T4 intron could have arisen. The extra $491 \mathrm{bp}$ in the RB3 intron is flanked by direct repeats of 12/15-bp identity. Direct repeats have been shown to be hot spots for deletion formation in T4 as well as in other organisms (Singer and Westlye 1988). We propose that the T4 copy of the $\operatorname{nrdB}$ intron has suffered a simple deletion event, as shown in Figure 3.

\section{Proposed structure of the intron}

Figure 4 shows the proposed secondary structure of the RB3 intron, which, like the T4 intron, is a typical group IA intron, drawn according to conventions laid down by Burke et al. (1987). The stem-loop structures drawn here are considered well-proven for the group IA introns on phylogenetic and experimental grounds (Burke 1988; Cech 1988). The T4 and RB3 intron structures differ by two single-base deletions and six base substitutions.

All four of the base changes in canonical group IA stem structures maintain the proposed base-pairing. These compensatory changes add to the already considerable support for the existence of the P6 and P9 pairings (Burke 1988). The P9 changes are particularly noteworthy; the primary sequence of the $\mathrm{P} 9$ stem is identical in all three T4 introns. It may be that the homogeneous P9 sequence seen in the T4 introns (or even the overall high level of similarity between the phage introns) is the result of interintron sequence conversions of the type observed by Bryk and Belfort (1990), in which several suppressors of 
5' splice site

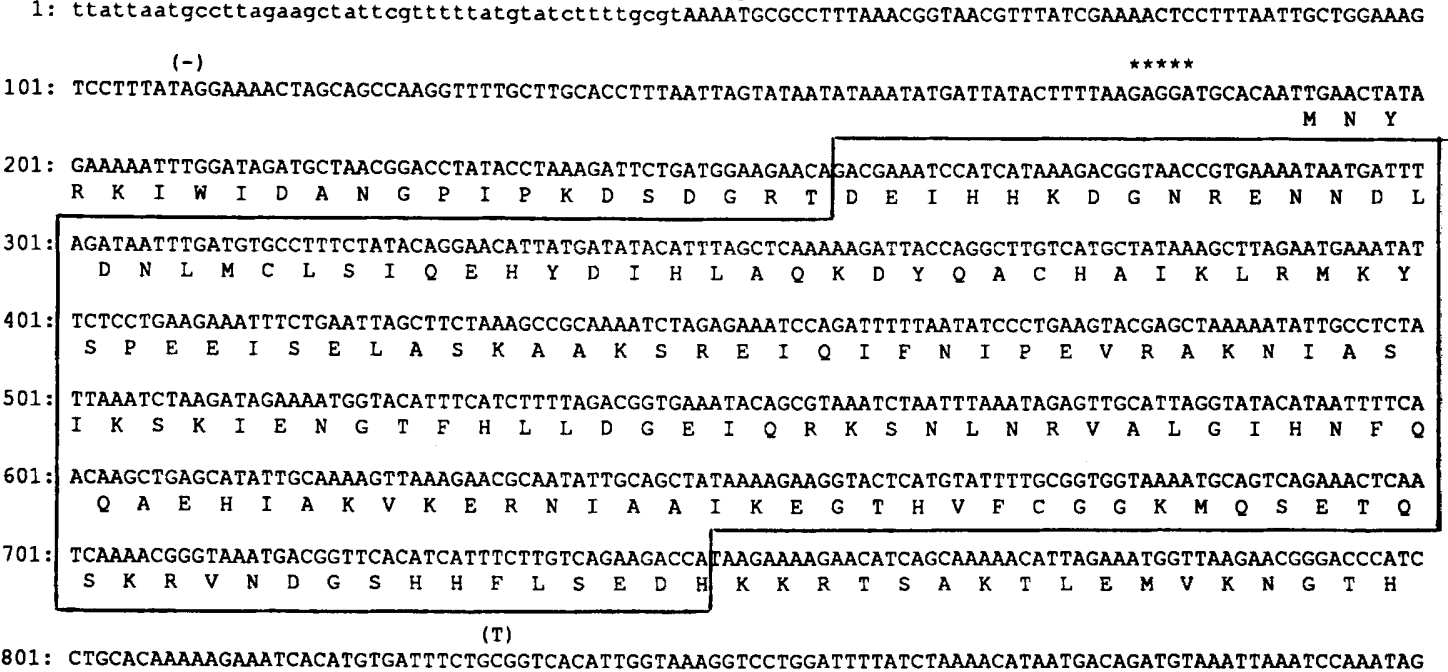

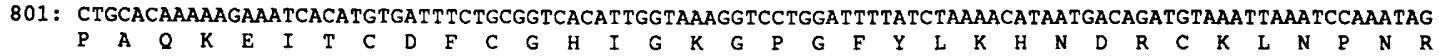

(A)

901: AATTCAATTGAATTGTCCATATTGTGATAAGAAAGATTTATCACCATCAACATATAAACGATGGCACGGCGACAATTGCAAAGCAAGGTCAACGACTAG

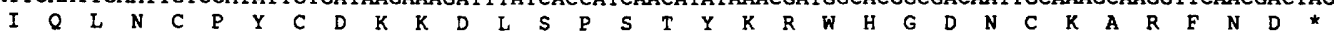

(C) (A) (G) (C) (C)

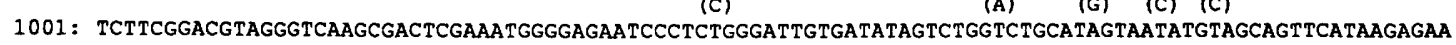

(-) 3' splice site

1101: CGGGTTGAGAATTAGCGAGCTCAATCGAACATAACGgtacct t aact tccataagaacatggaaatcatggaaggtaatgccaagattatgaagt cat

(t)

(c)

(c)

1201: tgcacgcgatgaacagcttcaccttaaaggcactcaatatattattcgtcaact caatccggtactgatggtgatgaatgggttaaattgctcaagag

(g) (c) (t)

1301: tgtgaacaagaagcagttgatattttcatggaagttaaccgccaagaaaagattgggcagttcatttatttaagatggcgatgttcctggattaaata

(c)

1401: caatagcatgtggagctttattgattacttaactgtatetcgtatgaaacagtgtggtettcca

Figure 2. DNA sequence of the RB3 $n r d B$ intron and parts of the flanking exons. Uppercase letters represent the intron itself; lowercase letters denote the exons. The predicted amino acid sequence of the intron ORF is indicated beneath the nucleotide sequence, beginning with a TTG initiation codon; the presumed Shine-Dalgarno sequence for this initiation codon is denoted by stars. The box superimposed on the intron ORF sequence encloses the 491 bases that T4 lacks. Two single-base deletions and 14 base substitutions that RB3 and T4 differ by in this region are noted by the T4 sequence above the RB3 sequence at the appropriate position.

defects in the $t d$ P7.1 pairing were found to reflect conversion events that replaced the $t d$ P7.1 with its homologous counterpart in sunY. Sequence conversions between similar but ectopic sequences seem to have gen- erated some of the classic rIIB mutants as well (Shinedling et al. 1987).

One of the base substitutions alters a newly proposed secondary structure element called P9.0, which is in- phage RB3:
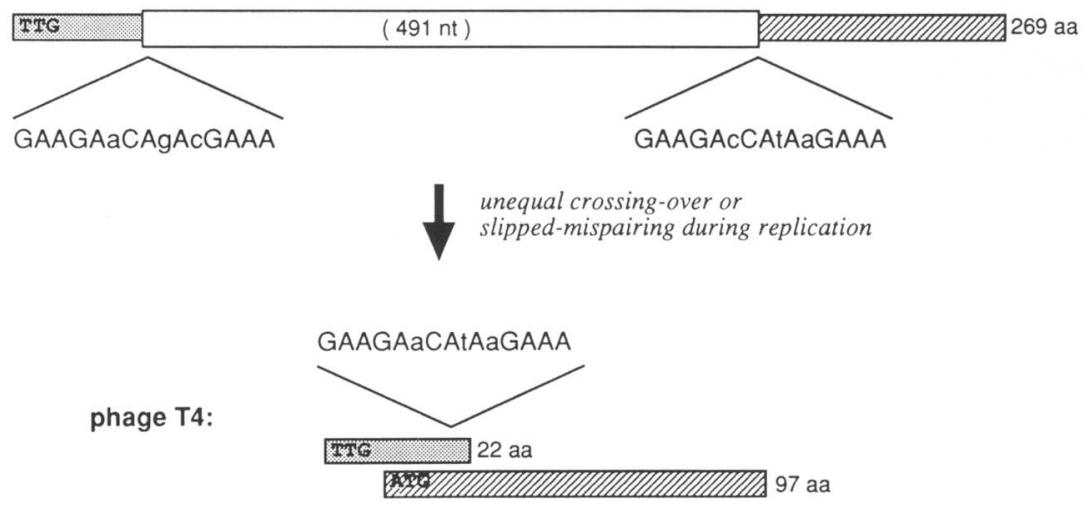

Figure 3. Proposed formation of the T4 intron from an RB3-like ancestor. The 269codon ORF in RB3 contains two near-perfect direct repeats, of 12/15-bp identity, separated by 476 nucleotides of sequence. We propose that either unequal crossing over during recombination or slipped mispairing during replication deleted these $476 \mathrm{bp}$ and one of the 15 -bp repeats, to introduce the 491-bp deletion seen in T4. This deletion frameshifts the remainder of the intron ORF, leading to the overlapping ORF structures in $\mathrm{T} 4$ that have been noted previously (Gott et al. 1986, 1988; Shub et al. 1988; Liu 1990). 
Figure 4. Proposed structure of the RB3 nrdB intron, drawn according to the previously proposed structure for the T4 intron (Shub et al. 1988) and the structural conventions for group LA introns (Burke et al. 1987). The base substitutions by which T4 and RB3 differ in this structure are indicated by arrows, with the T4 sequence in parentheses. The long-range pairing P9.0 is also indicated.

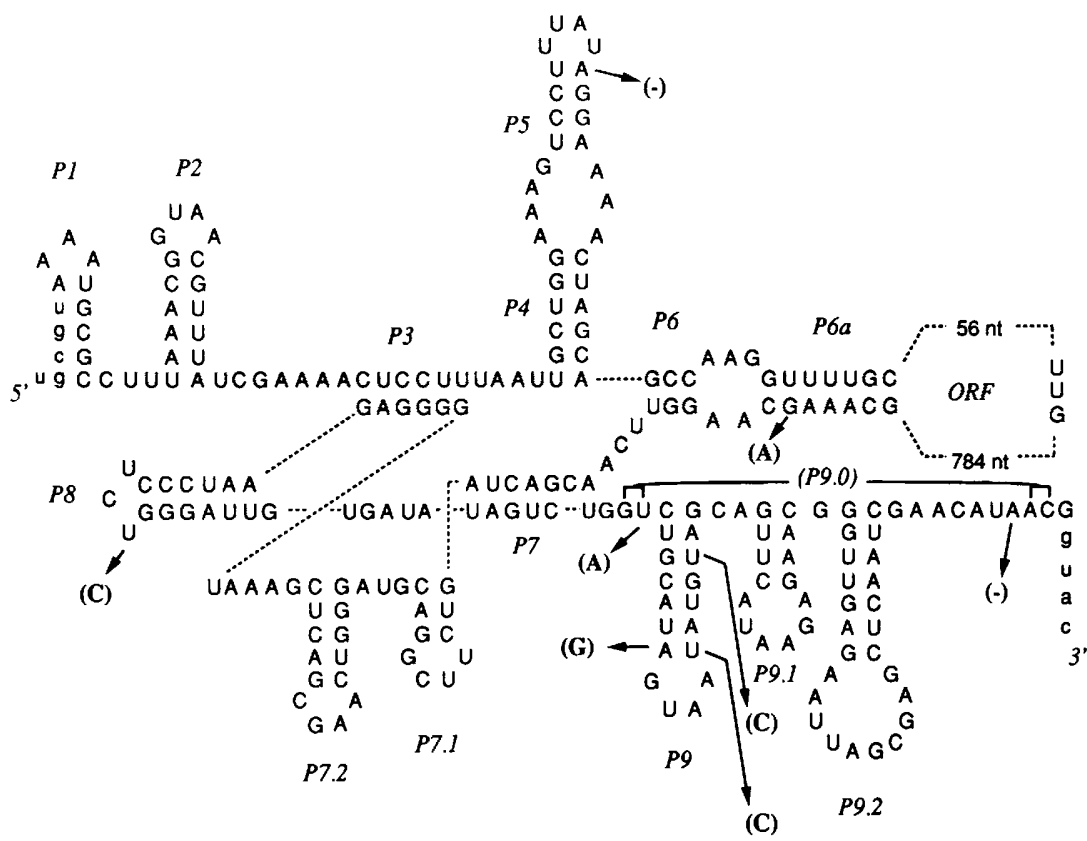

changed the translational initiation region to eliminate the occluding secondary structure (Gott et al. 1988), using instead a version of a strong ribosome-binding site, called SD8, studied previously in our laboratory (Gold and Stormo 1990). We also changed the initiation codon itself from a UUG to an AUG. These changes were introduced by means of PCR, by designing a $5^{\prime}$ primer (5'NOX; for the exact sequence, see Table 1) tagged with the desired changes and a convenient restriction site (Innis et al. 1990).

All nine constructs were transformed into the T7 RNA polymerase-producing host BL21/DE3 (Studier and Moffatt 1986). Upon IPTG induction of the T7 RNA polymerase, these constructs vastly overproduced a protein of $\sim 31 \mathrm{kD}$ not produced by cells that carried the starting vector pDIP19C alone. Small mobility shifts were seen in some of the substitution mutants, which provided further assurance that the protein being overexpressed was encoded by the gene that we had cloned.

\section{In vivo endonuclease activity}

We predicted that the intron ORF product should cleave an intronless $n r d B$ gene at or near the site of intron insertion. We infected briefly induced pNOX17(BL21/DE3) cells with a high multiplicity of $\mathrm{T}^{2} n \mathrm{ndBIn}{ }^{-}$phage, allowed $5 \mathrm{~min}$ for adsorption and injection of the phage chromosomes into the ORF-expressing cells, and stopped the infection on ice and extracted cellular and phage DNA. Extensions from a primer annealing just downstream of the $n r d B$ intron insertion point revealed a double-strand (dsDNA) break that was induced in ORFexpressing cells but not in vector-only negative controls (Fig. 5A). We assume that the ORF encodes this endonuclease activity, although it is possible that the 
Table 1. Oligonucleotide sequences

\begin{tabular}{|c|c|}
\hline $\begin{array}{l}\text { Primer } \\
\text { name }\end{array}$ & Sequence \\
\hline & PCR fingerprinting \\
\hline TD125 & CCCGGATCCGTGATTTTGGTGGTGTAGAC \\
\hline TD264 & CCCGGATCCAAAGCTCT T TAGGT TCACGCC \\
\hline N114 & CCCGGATCCTCTTTACCTCTGTTTGCACG \\
\hline N215 & CCCGGATCCGGAGCA T CGGTAATTGGGC \\
\hline SY259 & CCCGGATCCGCT TCT CACCAATACGGCGGAACG \\
\hline SY389 & CCCGGATCCAGTCCAGTCAGT TCCCGTACC \\
\hline g32-511 & CTGAAGATAAAGGCGAGTGGAAAC \\
\hline g32-564 & GT T TGGAATCGCAGATTGATTCAGG \\
\hline g43-2048 & CGGCCAAGTCGGTAT TCAGTGG \\
\hline g43-2079 & GCGGAGGGCAAGAAATAGCT T CACGG \\
\hline $\begin{array}{l}5^{\prime} \text { NOX } \\
\text { N195 }\end{array}$ & $\begin{array}{l}\text { Cloning } \\
\text { CCCGGATCCTAAGGAGGAATATAAAATGAACTATAGAAAAATTTGGATAG } \\
\text { GGGGCATGCT TCTTGTTCACACTCT TG }\end{array}$ \\
\hline $\begin{array}{l}\text { N101 } \\
\text { N180 }\end{array}$ & $\begin{array}{l}\text { Primer extensions } \\
\text { CCCGGATCCATTGGGCGATAT TACGATG } \\
\text { CCATGTTCTTATGGAAGTTAAAGGT }\end{array}$ \\
\hline
\end{tabular}

Sequences of oligonucleotides used in this study. Sequences are written $5^{\prime}$ to $3^{\prime}$. The first six PCR fingerprinting primers listed include $B a m H I$ sites at their 5 ' ends to facilitate subcloning. The $5^{\prime}$ NOX cloning primer replaces the translational initiation region of the $n r d B$ intron ORF with the strong Shine-Dalgarno sequence TAAGGAGG and a spacing of 8 nucleotides to an ATG initiation codon. All of the sequences that these primers anneal to are available on the GenBank sequence data base.

ORF product must interact with or modify other cellular gene products.

Alignment of primer extension products with sequencing ladders generated from the primers on both strands permitted us to see the precise location of the dsDNA break (Fig. 5B). In other repetitions of this experiment (not shown here) there is some apparent degradation of the cut ends that varies in extent from experiment to experiment, resulting in a doublet rather than a single band at the cut site.

The unidirectional nature of the gene conversion event that gives rise to intron mobility requires that the dsDNA break occur only in the intronless phage DNA and not in the intron-plus donor. Figure $5 \mathrm{C}$ shows the results of an experiment in which we learned that the intron-plus T4 genome is indeed immune to the activity of the ORF product at this site. The ORF-directed cut is specific for an intronless genome.

Figure 5D summarizes these results and shows the location of the dsDNA break on the sequence of an intronless $n r d B$ gene. The cut site is located $14-16$ bases upstream of the intron insertion site. It has a 2-base $5^{\prime}$ overhang. All other intron-encoded endonucleases studied so far leave 2- to 4-base $3^{\prime}$ overhangs. This difference may be relevant; to date, our preliminary experiments have not demonstrated that this endonuclease promotes $n r d B$ intron mobility (experiments not shown) in plasmid to In ${ }^{-}$phage mobility experiments similar to those done for sunY and $t d$ (Quirk et al. 1989b).

\section{Discussion}

An nrdB-specific intron-encoded endonuclease

Although the T4 nrdB intron is clearly not a mobile in- tron, a related phage, RB3, contains a longer form of the $n r d B$ intron that may prove to be mobile. The RB3 $n r d B$ intron encodes an endonuclease specific for an intronless $n r d B$ gene, a hallmark of the known mobile group I introns. The $\mathrm{T} 4$ intron appears to be a simple deletion mutant of an RB3-like ancestor. In accordance with existing nomenclature for intron-encoded endonucleases (Dujon et al. $1989 \mathrm{~b}$ ), we now refer to the RB3 $\mathrm{nrdB}$ intron ORF gene as the gene $I$-TevIII (intron-encoded T-even endonuclease III, where I and II are encoded by the introns in $t d$ and $\operatorname{sun} Y$ ).

The known examples of eukaryotic intron-encoded endonucleases all cut at or very close to the point of intron insertion. I-TevIII shares with the other two T4 intronencoded endonucleases the peculiar characteristic of cutting at a distance from the point of intron insertion. The $t d$ endonuclease cuts $23-26$ bp upstream of the intron insertion site; the sunY endonuclease cuts 13-15 bp downstream of the intron insertion site (Bell-Pedersen et al. 1990). I-TevIII cuts $14-16$ bp upstream of the $n r d B$ intron insertion site. Because intron insertion disrupts the ability of these endonucleases to recognize and cut the gene, we presume that their recognition sites must span the exon 1-exon 2 junction; therefore, the cuts are likely to occur outside the actual recognition site itself. This ability to cut at a precise distance away from a recognition site is reminiscent of the so-called type IIS subclass of restriction endonucleases (Szybalski 1985). The significance, if any, of this difference between the phage intron endonucleases and their eukaryotic counterparts is not known.

We note again that so far we have been unable to demonstrate that I-TevIII catalyzes mobility of the RB3 or the T4 $n r d B$ intron (work in progress). Keeping this ca- 

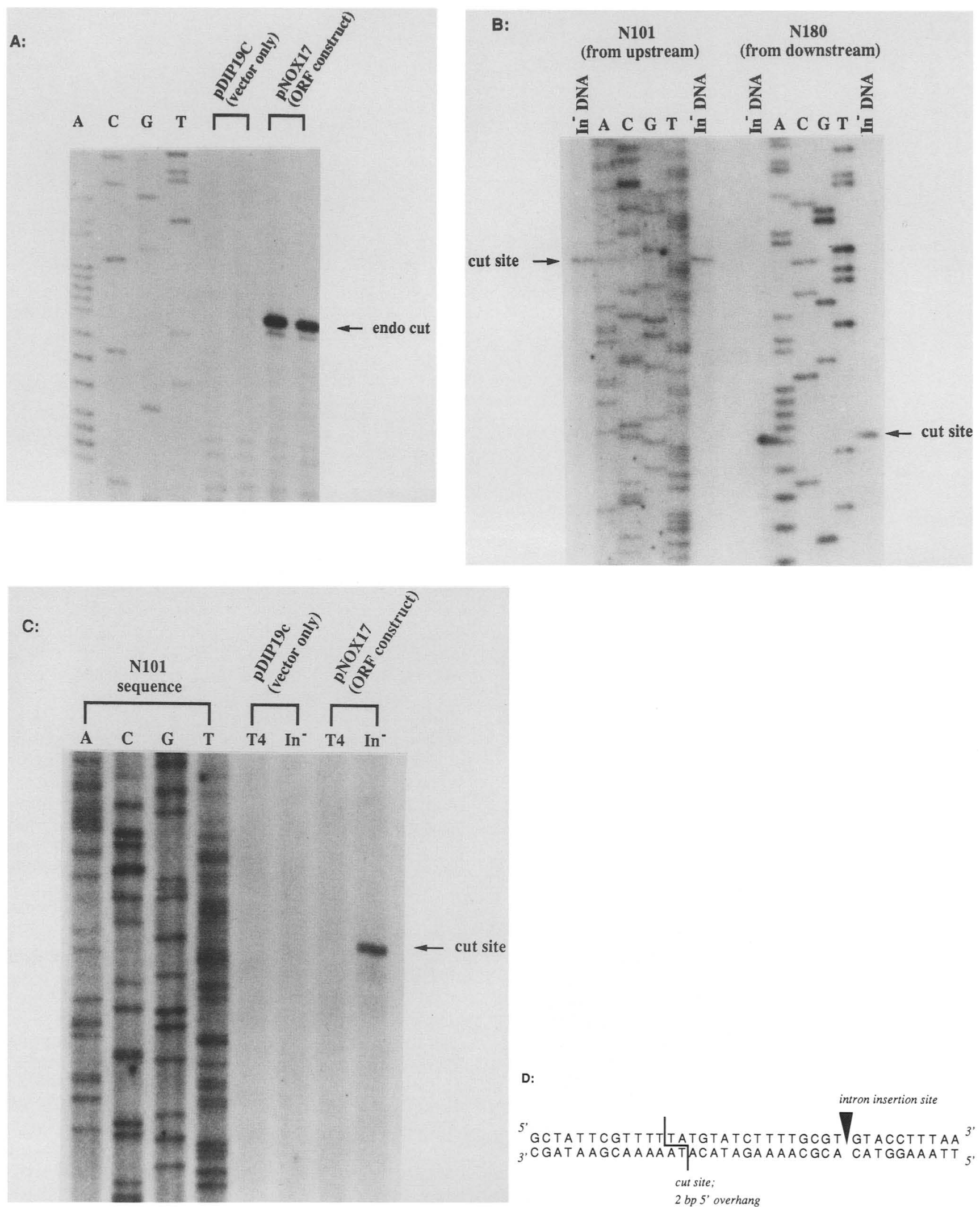

D:

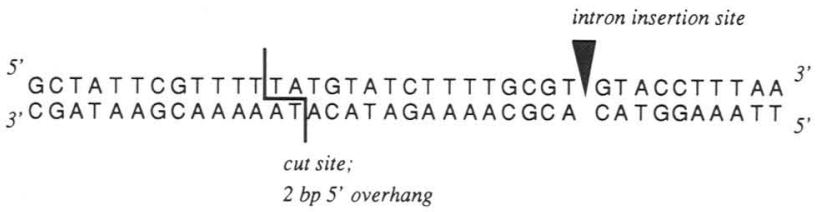

Figure 5. (See facing page for legend.) 
veat in mind, it nevertheless appears likely that not just two but all three $\mathrm{T}$-even phage introns are (or were) mobile elements. We think it likely that the $\mathrm{T} 4$ introns are parasites (or, more properly, commensals, as they do not seem to confer a measurable selective disadvantage or advantage on their host viral genome) (S.R. Eddy and L. Gold, unpubl.); they have been established and maintained in phage genomes by virtue of high-frequency conversion of intronless genomes in the population (Belfort 1989). The peculiar occurrence of the introns in genes of related functions is still mysterious and worthy of further consideration (Goodrich-Blair et al. 1990).

The evolutionary volatility of group I intron ORFs is becoming more and more apparent (Michel and Cummings 1985; Mota and Collins 1988). Our interpretation that phage T4 carries an immobile, deleted version of a mobile intron suggests to us that previous intron mobility may explain the presence and phylogenetic distribution of the other currently immobile group I introns, possibly including stripped-down ORF-less introns such as the canonical 26S rRNA intron in Tetrahymena. These introns may well have been mobile introns that lost their endonucleases at some point in their evolutionary history.

\section{Materials and methods}

Media

Hershey broth (HB), EHA plates, and EHA top agar were all prepared as described by Steinberg and Edgar (1962).

\section{Phage and bacterial strains}

The RB phage are a collection of 31 phage isolated from seven different sewage treatment plants on Long Island, New York, as part of a Cold Spring Harbor summer course in 1964 (Russell and Huskey 1974). They were defined as T-even-like primarily by the criterion that their infectivity could be neutralized by anti-T4 sera. We obtained 24 of these phage from W. Wood's collection in Boulder, Colorado. RB3 is one of eight isolates from Huntington, New York. The T phages T2L, T4D, T6, and T7 were from our laboratory's phage collection. T3 was provided by William Studier, and T5 was provided by Jim McCorquodale. The triple intron deletion strain of $\mathrm{T} 4$ was provided by David Shub. Phage stocks were grown according to Steinberg and Edgar (1962) using an E. coli B strain NAP IV (Nelson et al.
1982) as the host. The T7 polymerase expressing E. coli strain BL21/DE3 was provided by William Studier.

\section{PCR fingerprinting}

A single phage plaque $\left(\sim 10^{7}\right.$ phage $)$ was picked with a sterile Pasteur pipette and suspended in $100 \mu \mathrm{l}$ of distilled water. Of this, $40 \mu \mathrm{l}$ was used as template DNA in a $100-\mu 1$ PCR reaction that was composed of $50 \mathrm{mM} \mathrm{KCl}, 10 \mathrm{~mm}$ Tris-Cl at $\mathrm{pH} 8.6,2.5$ $\mathrm{mm} \mathrm{MgCl} 2,170 \mu \mathrm{g} / \mathrm{ml} \mathrm{BSA}, 400 \mu \mathrm{M}$ of each of the four dNTPs, 50 pmoles of each of 10 oligonucleotide primers (see below), and 3 units of Taq DNA polymerase (Promega). These were covered with mineral oil and incubated for 50 cycles of $95^{\circ} \mathrm{C}$ for $1 \mathrm{~min}$, $50^{\circ} \mathrm{C}$ for $1 \mathrm{~min}$, and $70^{\circ} \mathrm{C}$ for $4 \mathrm{~min}$. One-tenth of this reaction was run out on a $1.4 \%$ agarose gel, which was stained in ethidium bromide and photographed under short-wave UV illumination. The oligonucleotide primers used to generate a $\mathrm{T}$-even fingerprint were designed to amplify portions of five genes. Two of the products are from genes 32 and 43 , essential genes that we presumed would be conserved among all $\mathrm{T}$-even-like phage. The other three products are from the three intron-containing genes $t d, n r d B$, and sun $Y$ of phage T4. The primers for these amplification products anneal to exon sequences flanking the intron insertion site; therefore, phage-containing introns amplify large bands and phage without introns give small bands in the resulting fingerprint. The sequences of the primers used are shown in Table 1.

\section{DNA sequencing}

Single-stranded (ssDNA) sequencing templates were generated by asymmetric PCR of RB3 phage (Innis et al. 1990). The PCR reaction was carried out exactly as above, except only the two $n r d B$-specific primers N114 and N215 were present in the reaction: 25 pmoles of one, and 0.25 pmole of the other. The products of this reaction (primarily ssDNA) were partially purified by phenol extraction, chloroform extraction, passage over a Sephadex G-50 spin column, and ethanol precipitation. (The G-50 step is crucial; otherwise, significant amounts of dNTPs are carried over from the PCR reaction and the $\mathrm{dNTP} / \mathrm{ddNTP}$ ratio in sequencing reactions is badly skewed.) Enough template is generated from one $100-\mu$ PCR reaction to do two or three sequencing reactions. Better results were obtained when the length of the amplified product was short; therefore, templates for many sequencing reactions were generated using PCR primers as close as possible to the annealing site of the sequencing primer. Sequencing was performed by the dideoxy chain-termination method, using a modified T7 DNA polymerase (Sequenase; U.S. Biochemical) essentially as recommended by the

Figure 5. The cloned intron ORF produces a DNA endonuclease specific for an intronless nrdB gene. $(A)$ Lanes $A, C, G$, and $T$ are a sequencing ladder on $n r d B I^{-}$plasmid template. Shown in the other lanes are results of primer extensions on $n r d B I n{ }^{-} \mathrm{T} 4 \mathrm{DNA}$ isolated shortly after infection of expression plasmid-containing cells, where the plasmid is either the starting vector pDIP19C alone or pNOX17, which transcribes a wild-type copy of the ORF-coding sequence. In this particular experiment, two independent preparations of phage DNA were assayed for each of the two plasmids. The primer used is N180, which anneals just downstream of the intron insertion point. The region of the sequence examined here is immediately upstream of the intron insertion point. $(B)$ More precise alignment of the cut site, with sequencing ladders on both strands. Extensions were performed with a primer N101, which anneals $\sim 200$ bases upstream, and the primer N180, which anneals immediately downstream of the cut site, and aligned with sequencing ladders made with the same primers. The cut is present on both strands. $(C)$ Essentially the same as the experiment in $A$, except that intron-plus T4 DNA is also tested as a substrate. The upstream primer N101 is used here for primer extensions rather than $\mathrm{N} 180$, as N180 anneals to exon 2 and thus gives different sequence ladders on intron-plus and intronless DNA. Only the intronless DNA is recognized and cut by the ORF product. $(D)$ Interpretation of the above results, showing the location of the cuts on both strands of the intronless $n r d B$ sequence. The cut is 14-16 nucleotides upstream of the intron insertion site and leaves an end with a 2-base 5 ' overhang. 
manufacturer, with $5^{\prime}-{ }^{32} \mathrm{P}$-end-labeled synthetic oligonucleotides as primers. Sequence was obtained from both strands of the DNA, using a total of 15 synthetic primers. On average, $\sim 300$ nucleotides could be read from each primer, and the primers were spaced 200-300 nucleotides apart on the DNA. There was a single place where a compression artifact appeared (positions 1067-1075, in the P8 stem of the catalytic structure of the intron|, and the sequence presented here is that read from the uncompressed strand.

\section{Cloning}

DNA manipulations were performed according to standard technique (Maniatis et al. 1982). The vector pDIP19C is a T7 expression vector with certain other features making it useful for T4 work that are not relevant to this paper (Singer and Gold 1991). Briefly, pDIP19C is a pACYC184 derivative $\left(\mathrm{Cam}^{\mathrm{R}}, \mathrm{pl}\right.$ A A origin) carrying the $\mathrm{T} 7 \phi 10$ promoter driving through the same multiple cloning site as that in pUC19. Primers $5^{\prime}$ NOX and N214 were used to amplify a modified RB3 $n r d B$ ORF from RB3 phage by PCR; this amplified fragment was phenol- and chloroform-extracted, precipitated, and cut with BamHI and KpnI, and the resulting 971 -bp fragment from the synthetic translational start of the gene to the $3^{\prime}$ end of the intron was gelpurified from a $1 \%$ agarose gel by electroelution onto DEAE paper. (We have found that gel purification of PCR-generated DNA for cloning is often necessary, to avoid cloning low-molecular-weight PCR artifacts-"primer dimers.") This insert was ligated into BamHI/KpnI-cut pDIP19C. Fifty transformants were picked, and nine were found to contain the insert. The insert of each of these constructs was completely sequenced on one strand, using ssDNA template generated by asymmetric PCR from $0.1 \mathrm{ng}$ of plasmid DNA (see above). Three of the constructs were found to be wild type in sequence (pNOX17, pNOX24, and pNOX48), three contained single-base substitutions, two had 2-base substitutions, and one (pNOX47) had three substitutions resulting in two predicted amino acid substitutions. All nine constructs were transformed into the host BL21/DE3 (an $E$. coli B strain carrying a $\lambda$ lysogen that produces T7 polymerase under IPTG-inducible lac promoter control; Studier and Moffatt 1986) for further work on overexpressing the protein. All nine overproduced a protein of $\sim 31 \mathrm{kD}$ upon IPTG induction that was not seen in uninduced cells or in induced cells carrying the parent pDIP19C vector.

\section{In vivo endonuclease activity}

pDIP19C or pNOX17 transformants of BL21/DE3 were grown to an $\mathrm{OD}_{600}$ of $\sim 0.6$ in a volume of $80 \mathrm{ml}$ of $\mathrm{HB}$ at $37^{\circ} \mathrm{C}$. These cultures were induced by the addition of IPTG to a $1 \mathrm{~mm}$ final concentration and incubated for an additional $5 \mathrm{~min}$. T4 $\mathrm{nrdB} \mathrm{In}^{-}$ or T4D phage at $2.4 \times 10^{10} \mathrm{phage} / \mathrm{ml}$ was added in a $20-\mathrm{ml}$ volume, and these infections were allowed to proceed for $5 \mathrm{~min}$ at $37^{\circ} \mathrm{C}$. Infected cells were poured into centrifuge bottles on ice, and DNA was harvested from them by a standard plasmid isolation protocol, which is essentially the lysozyme/ $\mathrm{NaOH} /$ SDS lysis protocol described by Silhavy et al. (1984).

One-fifth of the DNA harvested from this procedure was used as input template into primer extensions with Sequenase, using the same conditions as our primer extension sequencing but leaving out the dideoxynucleotides. (The cytosines in T4 DNA are hydroxymethylated and glucosylated. In our hands, AMV reverse transcriptase has failed to effectively extend primers annealed to T4 DNA. Sequenase-modified T7 DNA polymerase-extends on T4 DNA templates well enough for seeing signal from a simple primer extension, although not well enough to generate sequencing ladders. The sequencing ladders used to calibrate the experiments shown in Figure 5 were generated on double-stranded plasmid clones of the $n r d B$ precise intron deletion.) Reaction products were separated by gel electrophoresis on $8 \%$ polyacrylamide $-8 \mathrm{M}$ urea sequencing gels.

\section{Acknowledgments}

This work was supported by grants GM19963 and GM28685 from the National Institutes of Health. S.R.E. was supported by a National Science Foundation Graduate Fellowship. We also thank the W.M. Keck Foundation for their generous support of RNA science on the Boulder campus.

The publication costs of this article were defrayed in part by payment of page charges. This article must therefore be hereby marked "advertisement" in accordance with 18 USC section 1734 solely to indicate this fact.

\section{References}

Belfort, M. 1989. Bacteriophage introns: Parasites within parasites? Trends Genet. 5: 209-213.

_ 1990. Phage T4 introns: Self-splicing and mobility. Annu. Rev. Genet. 24: 363-385.

Bell-Pedersen, D., S.M. Quirk, M. Aubrey, and M. Belfort. 1989. A site-specific endonuclease and co-conversion of flanking exons associated with the mobile $t d$ intron of phage $\mathrm{T} 4$. Gene 82: 119-126.

Bell-Pedersen, D., S. Quirk, J. Clyman, and M. Belfort. 1990. Intron mobility in phage $\mathrm{T} 4$ is dependent upon a distinctive class of endonucleases and independent of DNA sequences encoding the intron core: Mechanistic and evolutionary implications. Nucleic Acids Res. 18: 3763-3770.

Bryk, M. and M. Belfort. 1990. Spontaneous shuffling of domains between introns of phage T4. Nature 346: 394-396.

Burger, G. and S. Werner. 1985. The mitochondrial URF1 gene in Neurospora crassa has an intron that contains a novel type of URF. I. Mol. Biol. 186: 231-242.

Burke, J.M. 1988. Molecular genetics of group I introns: RNA structures and protein factors required for splicing-A review. Gene 73: 273-294.

Burke, J.M., M. Belfort, T.R. Cech, R.W. Davies, R.J. Schweyen, D.A. Shub, J.W. Szostak, and H.F. Tabak. 1987. Structural conventions for group I introns. Nucleic Acids Res. 15: 7217-7221.

Burke, J.M., J.S. Esherick, W.R. Burfeind, and J.L. King. 1990. A 3 ' splice site binding sequence in the catalytic core of a group I intron. Nature 344: 80-82.

Cech, T.R. 1988. Conserved sequences and structures of group I introns: Building an active site for RNA catalysis-A review. Gene 73: 259-271.

Chu, F.K., G. Maley, J. Pedersen-Lane, A.-M. Wang, and F. Maley. 1990. Characterization of the restriction site of a prokaryotic intron-encoded endonuclease. Proc. Natl. Acad. Sci. 87: 3574-3578.

Cummings, D.J., F. Michel, and K.L. McNally. 1989. DNA sequence analysis of the apocytochrome $\mathrm{b}$ gene of Podospora anserina: A new family of intronic open reading frame. Curr. Genet. 16: 407-418.

Delahodde, A., V. Goguel, A.M. Becam, F. Creusot, J. Perea, J. Banroques, and C. Jacq. 1989. Site-specific DNA endonuclease and RNA maturase activities of two homologous intron-encoded proteins from yeast mitochondria. Cell 56: 431-441.

Doolittle, W.F. 1987. What introns have to tell us: Hierarchy in 
genome evolution. Cold Spring Harbor Symp. Quant. Biol. 52: 907-913.

Doolittle, R.F., D.-F. Feng, M.S. Johnson, and M.A. McClure. 1989. Origins and evolutionary relationships of retroviruses. Q. Rev. Biol. 64: 1-30.

Dujon, B. 1989. Group I introns as mobile genetic elements: Facts and mechanistic speculations-A review. Gene 82: 91-114.

Dujon, B., M. Belfort, R.A. Butow, and C. Jacq, C. Lemieux, P.S. Perlman, and V.M. Vogt. 1989. Mobile introns: Definition of terms and recommended nomenclature. Gene 82: 115-118.

Gold, L. and G.D. Stormo. 1990. High-level translation initiation. Methods Enzymol. 185: 89-93.

Goodrich-Blair, H., V. Scarlato, J.M. Gott, M.-Q. Xu, and D.A. Shub. 1990. A self-splicing group I intron in the DNA polymerase gene of Bacillus subtilis phage SPO1. Cell 63: 417-424.

Gott, J.M., D.A. Shub, and M. Belfort. 1986. Multiple self-splicing introns in bacteriophage T4: Evidence from autocatalytic GTP labeling of RNA in vitro. Cell 47: 81-87.

Gott, J.M., A. Zeeh, D. Bell-Pedersen, K. Ehrenman, M. Belfort, and D.A. Shub. 1988. Genes within genes: Independent expression of phage $\mathrm{T} 4$ intron open reading frames and the genes in which they reside. Genes \& Dev. 2: 1791-1799.

Hensgens, L.A.M., L. Bonen, M. de Haan, G. van der Horst, and L.A. Grivell. 1983. Two intron sequences in yeast mitochondrial COX1 gene: Homology among URF-containing introns and strain-dependent variation in flanking exons. Cell 32: 379-389.

Hickey, D.A., B.F. Benkel, and S.M. Abukashawa. 1989. A general model for the evolution of nuclear pre-mRNA introns. $J$. Theor. Biol. 137: 41-53.

Innis, M.A., D.H. Gelfand, J.J. Sninsky, and T.J. White, eds. 1990. PCR protocols: A guide to methods and applications. Academic Press, San Diego, CA.

Jacquier, A. and B. Dujon. 1985. An intron-encoded protein is active in a gene conversion process that spreads an intron into a mitochondrial gene. Cell 41: 383-394.

Lambowitz, A.M. 1989. Infectious introns. Cell 56: 323-326.

Lang, B.F. 1984. The mitochondrial genome of the fission yeast Schizosaccharomyces pombe: Highly homologous introns are inserted at the same position of the otherwise less conserved coxl genes in Schizosaccharomyces pombe and Aspergillus nidulans. EMBO I. 3: 2129-2136.

Lemieux, B., M. Turmel, and C. Lemieux. 1988. Unidirectional gene conversions in the chloroplast of Chlamydomonas interspecific hybrids. Mol. Gen. Genet. 212: 48-55.

Liu, L. 1990. Expression of open reading frames in the intron of the $n r d B$ gene of bacteriophage T4. Master's thesis, State University of New York at Albany.

Maniatis, T., E.F. Fritsch, and J. Sambrook. 1982. Molecular cloning: A laboratory manual. Cold Spring Harbor Laboratory, Cold Spring Harbor, New York.

Michel, F. and D.J. Cummings. 1985. Analysis of class I introns in a mitochondrial plasmid associated with senescence of Podospora anserina reveals extraordinary resemblance to the Tetrahymena ribosomal intron. Curr. Genet. 10: 69-79.

Michel, F. and B. Dujon. 1986. Genetic exchanges between bacteriophage T4 and filamentous fungi? Cell 46: 323 .

Michel, F., P. Netter, M.-Q. Xu, and D.A. Shub. 1990. Mechanism of 3' splice site selection by the catalytic core of the sunY intron of bacteriophage T4: The role of a novel base-pairing interaction in group I introns. Genes \& Dev. 4: 777-788.

Mota, E.M. and R.A. Collins. 1988. Independent evolution of structural and coding regions in a Neurospora mitochondrial intron. Nature 332: 654-656.

Muscarella, D.E. and V.M. Vogt. 1989. A mobile group I intron in the nuclear rDNA of Physarum polycephalum. Cell 56: 443-454.

Nelson, M.A., M. Ericson, L. Gold, and J.F. Pulitzer. 1982. The isolation and characterization of tabR bacteria: Hosts that restrict bacteriophage T4 rII mutants. Mol. Gen. Genet. 188: $60-68$.

Pearson, W.R. and D.J. Lipman. 1988. Improved tools for biological sequence comparison. Proc. Natl. Acad. Sci. 85: 2444-2448.

Pedersen-Lane, J. and M. Belfort. 1987. Variable occurrence of the $n r d B$ intron in the T-even phages suggests intron mobility. Science 237: 182-184.

Perlman, P.S. and R.A. Butow. 1989. Mobile introns and intronencoded proteins. Science 246: 1106-1109.

Quirk, S.M. D. Bell-Pedersen, J. Tomaschewski, W. Ruger, and M. Belfort. 1989a. The inconsistent distribution of introns in the T-even phages indicates recent genetic exchanges. $\mathrm{Nu}$ cleic Acids Res. 17: 301-314.

Quirk, S.M. D. Bell-Pedersen, and M. Belfort. 1989b. Intron mobility in the T-even phages: High frequency inheritance of group I introns promoted by intron open reading frames. Cell 56: $455-465$.

Russell, R.L. and R.J. Huskey. 1974. Partial exclusion between T-even bacteriophages: An incipient genetic isolation mechanism. Genetics 78: 989-1014.

Scazzocchio, C. 1989. Group I introns: Do they only go home? Trends Genet. 5: 168-172.

Shinedling, S., B.S. Singer, M. Gayle, D. Pribnow, E. Jarvis, B. Edgar, and L. Gold. 1987. Sequences and studies of bacteriophage T4 rII mutants. I. Mol. Biol. 195: 471-480.

Shub, D.A., J.M. Gott, M.-Q. Xu, B.F. Lang, F. Michel, J. Tomaschewski, J. Pedersen-Lane, and M. Belfort. 1988. Structural conservation among three homologous introns of bacteriophage T4 and the group I introns of eukaryotes. Proc. Natl. Acad. Sci. 85: 1151-1155.

Silhavy, T.J., M.L. Berman, and L.W. Enquist. 1984. Experiments with gene fusions. Cold Spring Harbor Laboratory, Cold Spring Harbor, New York.

Singer, B.S. and L. Gold. 1991. Development of a T4 expression vector. Gene (in press).

Singer, B.S. and J. Westlye. 1988. Deletion formation in bacteriophage T4. I. Mol. Biol. 202: 233-243.

Steinberg, C.M. and R.S. Edgar. 1962. A critical test of a current theory of genetic recombination in bacteriophage. Genetics 47: 187-208.

Studier, F.W. and B.A. Moffatt. 1986. Use of bacteriophage T7 RNA polymerase to direct selective high-level expression of cloned genes. I. Mol. Biol. 189: 113-130.

Szybalski, W. 1985. Universal restriction endonucleases: Designing novel cleavage specificities by combining adapter oligodeoxynucleotide and enzyme moieties. Gene 40: 169-173.

Trinkl, H. and K. Wolf. 1986. The mosaic coxI gene in the mitochondrial genome of Schizosaccharomyces pombe: Minimal structural requirements and evolution of group I introns. Gene 45: 289-297.

Waring, R.B., T.A. Brown, J.A. Ray, C. Scazzocchio, and R.W. Davies. 1984. Three variant introns of the same general class in the mitochondrial gene for cytochrome oxidase subunit 1 in Aspergillus nidulans. EMBO J. 3: 2121-2128.

Wenzlau, J.M., R.J. Saldanha, R.A. Butow, and P.S. Perlman. 1989. A latent intron-encoded maturase is also an endonuclease needed for intron mobility. Cell 56: 421-430.

White, H.B. III. 1982. Evolution of coenzymes and the origin of pyridine nucleotides. In The pyridine nucleotide coenzymes (ed. J. Everse, B. Anderson, and K. Youl, pp. 1-17. Academic Press, New York. 


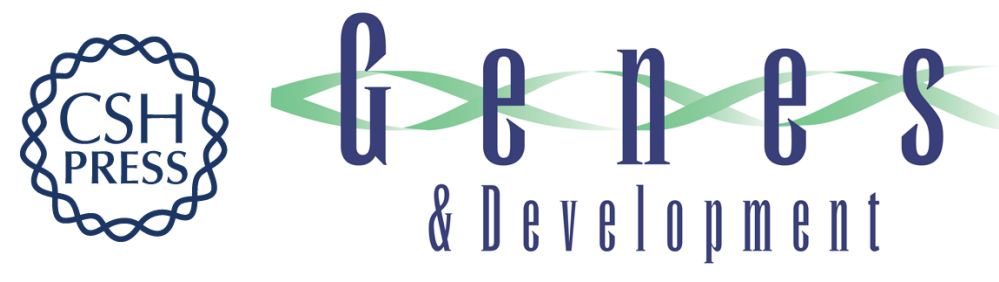

\section{The phage T4 nrdB intron: a deletion mutant of a version found in the wild.}

S R Eddy and L Gold

Genes Dev. 1991, 5:

Access the most recent version at doi:10.1101/gad.5.6.1032

References This article cites 49 articles, 10 of which can be accessed free at:

http://genesdev.cshlp.org/content/5/6/1032.full.html\#ref-list-1

License

Email Alerting Receive free email alerts when new articles cite this article - sign up in the box at the top Service right corner of the article or click here.

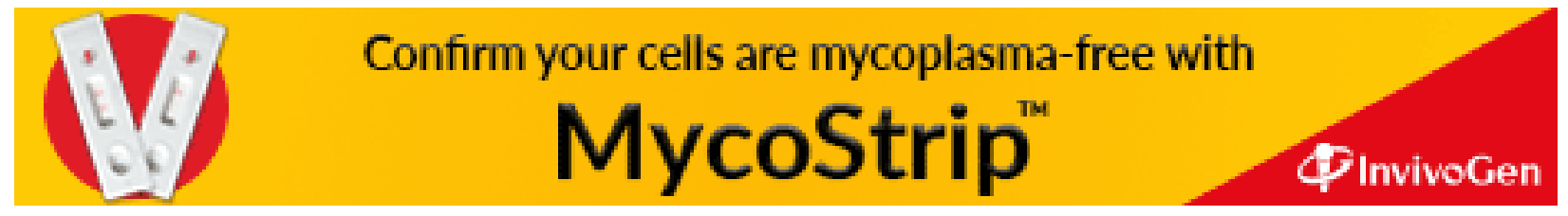

